DOI: doi.org/10.21009/JRMSI.011.2.03

\title{
PERAN DUKUNGAN ORGANISASI UNTUK MENINGKATKAN RETENSI KARYAWAN BANK X
}

\author{
Intan Dwi Rizky \\ Fakultas Psikologi, Universitas Indonesia \\ Email: intandwie26@gmail.com \\ Martina Dwi Mustika \\ Fakultas Psikologi, Universitas Indonesia \\ Email: martinadwimustika@gmail.com
}

\begin{abstract}
ABSTRAK
Retensi karyawan perlu dilakukan agar organisasi tidak mengalami kerugian akibat biaya rekruitmen yang tinggi. Retensi karyawan dapat dilakukan salah satunya dengan menggunakan program pengembangan karir yang juga merupakan salah satu dukungan organisasi bagi karyawan. Penelitian ini merupakan penelitian korelasional kuantitatif yang bertujuan menentukan dan menjelaskan peran mediasi dukungan organisasi (POS) terhadap hubungan Program Pengembangan Karir (CDP) dengan retensi karyawan pada Bank X. Seratus enam puluh lima orang karyawan dari berberapa kantor cabang yang telah bekerja minimal 1 tahun berpartisipasi pada penelitian ini. Data dianalisa dengan menggunakan metode analisa korelasi dan regresi. Hasil menunjukkan adanya hubungan tidak langsung yang signifikan antara Program CDP terhadap retensi karyawan melalui peran dukungan organisasi (POS). Dapat disimpulkan bahwa Program CDP bermanfaat untuk mempertahankan karyawan karena merupakan dukungan organisasi yang cukup nyata dirasakan karyawan secara langsung.
\end{abstract}

Kata Kunci : Career Development Program (CDP), Perceived Organizational Support (POS), retention. 


\section{PENDAHULUAN}

Organisasi adalah kolaborasi sekelompok orang yang dilakukan berulang sehingga membentuk pola teratur dan menjadi sebuah sistem untuk mencapai suatu tujuan (Umam, 2010). Aspek terpenting agar organisasi dapat mencapai tujuannya adalah karyawan (Kaplan \& Norton, 2004). Bila tidak dikelola dengan baik, karyawan sebagai sumber daya manusia dalam organisasi dapat meninggalkan organisasi (turnover) sehingga sistem organisasi tidak berjalan lancar. Hal ini juga dialami oleh beberapa pelaku industri perbankan akibat diberlakukannya program digitalisasi sistem perbankan (Mohamad, 2019). Program digitalisasi sistem perbankan ini mengakibatkan terjadinya pengurangan sumber daya manusia yang cukup signifikan. Salah satu bank di Indonesia kemudian merumukan kebijakan dengan mengoptimalisasi kinerja karyawan sehingga mereka tetap bekerja di organisasi.

Lebih dari 20 karyawan Bank X mengajukan pengunduran diri dari organisasi di setiap cabang di wilayah Jabodetabek pada dua tahun terakhir. Pada 2019, jumlah karyawan yang mengundurkan diri di setiap cabang hampir 10-15 orang, yang merupakan jumlah yang cukup tinggi untuk industri perbankan. Bank X memilih strategi untuk mengoptimalkan sumber daya manusia yang mereka miliki saat ini. Tujuan dari optimalisasi ini adalah agar setiap karyawan dapat berpartisipasi dan berkembang bersama perusahaan seiring dengan perubahan dalam industri perbankan saat ini. Untuk alasan ini, penting bagi manajemen untuk menjaga karyawan dalam organisasi (retensi karyawan). Retensi karyawan adalah pada cara yang digunakan oleh perusahaan untuk mempertahankan karyawan dalam organisasi untuk jangka waktu yang lama (Ragupathi, 2013) sehingga tujuan organisasi dapat tercapai (Wijayanti \& Nurtjahjanti, 2015). Salah satu strategi yang digunakan adalah upaya memprioritaskan pengembangan kompetensi karyawan melalui peningkatan keterampilan teknis dan pengembangan bakat. Career Development Program (CDP) kemudian diperkenalkan untuk meningkatkan retensi karyawan Bank X. Dalam CDP ini, Bank X menjalankan proses rotasi dan mutasi setiap karyawan di segala bidang kerja yang ada untuk memperkaya pengetahuan setiap karyawan, sebelum akhirnya karyawan mendapat promosi ke jalur karier yang lebih tinggi.

Pemberikan program CDP kepada karyawan dapat dianggap sebagai salah satu bentuk dukungan organisasi bagi kemajuan karir sumber daya manusia (Allen et al., 2003). Program CDP tidak selalu berbentuk promosi, tetapi juga dapat berupa pengembangan karir melalui pengalaman kerja (Gomez-meija et al., 2011). Pengalaman kerja didapatkan karyawan dengan 
cara proses pembelajaran dan pengembangan pengetahuan melalui perpindahan posisi dari satu jabatan ke jabatan lainnya (Ohlott, 2004). Pemberian kesempatan kepada karyawan untuk mengembangkan pengetahuan melalui beragai pengalaman kerja menjadi bentuk dukungan organisasi terhadap karyawan, baik melalui pemberian training formal maupun informal (Wayne et al., 1997). Pada dasaranya, di dalam organisasi terdapat pertukaran antara karyawan dengan pemberi kerja, seperti pemberian upah maupun fasilitas lain dari organisasi terhadap karyawan, sehngga terjalin hubungan yang seimbang antar karyawan dengan organisasi (Eisenberger \& Huntington, 1986). Pemindahan karyawan ke posisi baru untuk meningkatkan pengembangan karier mereka adalah cara kunci bagi organisasi untuk berinvestasi pada karyawan. Dengan adanya dukungan oganisasi (POS) dapat berpengaruh terhadap kesediaan karyawan untuk tetap berada di organisasi (Wayne et al., 1997).

\section{Rumusan Masalah}

Berdasarkan latar belakang permasalahan yang telah diuraikan sebelumnya, maka dapat dirumuskan permasalahan penelitian sebagai berikut: Apakah dukungan organisasi memediasi hubungan antara Program CDP dan retensi karyawan?.

\section{Tujuan Penelitian}

Tujuan penelitian ini ingin mengetahui jawaban dan saran yang dapat diberikan untuk mengembangkan atau optimalisasi program ODP pada Bank X untuk meningkatkan retensi karyawan. Oleh sebab itu, tujuan penelitian ini adalah untuk mengetahui seberapa jauh peran Perceived Organizatonal Support (POS) terhadap hubungan antara Program CDP dan retensi karyawan.

\section{TELAAH PUSTAKA}

\section{Retensi Karyawan}

Retensi karyawan harus diperhatikan oleh organisasi sebagai upaya mempertahankan karyawan yang kompeten untuk tetap bekerja dan berpartisipasi dalam pengembangan organisasi (Jennifer, 2005). Proses untuk menemukan karyawan yang kompeten diawali dengan proses rekruitmen yang disertai pemberian serangkaian pelatihan untuk meningkatkan kemampuan dan pengetahuan karyawan. Hal ini bertujuan agar karyawan dapat bekerja dengan baik sebagai 
upaya mencapai tujuan organisasi. Komitmen karyawan untuk tetap dalam organisasi untuk berkembang dan juga tumbuh bersama organisasi sangat dibutuhkan. Ketika karyawan meninggalkan organisasi, pada dasarnya organisasi kehilangan aset tidak berwujud (intangible asset) yang dimiliki oleh perusahaan, dengan asumsi turut hilangnya pengetahuan yang dimiliki karyawan tersebut jika tidak ada transfer pengetahuan yang baik dalam organisasi (Mohapatra et al., 2016).

Beberapa faktor yang memengaruhi retensi karyawan secara signifikan adalah jenis kelamin dan gaji (Singh \& Sharma, 2018), motivasi, penghargaan, pengakuan, pelatihan dan pengembangan, promosi, gaji, keamanan dan lingkungan kerja (Kassa, 2015; Rhacyella \& Tielung, 2018), keterikatan misi dan komitmen organisasi dan keterlibatan karyawan (Fukofuka, 2014). Peluang pengembangan, kompensasi, keseimbangan kehidupan kerja, kepemimpinan, lingkungan kerja, dukungan sosial, otonomi, pelatihan dan pengembangan juga berkontribusi sebagai faktor penentu retensi karyawan (Kossivi et al., 2016). Pelaksanaan dan pemberian Career Development Program (CDP) juga dapat meningkatkan retensi karyawan karena keterampilan dan kemampuan karyawan menjadi lebih terasah (Chandiok, 2012; Mehta et al., 2014; Oladapo, 2014; Prince, 2005; Rafique Ahmad Khan, 2014).

\section{Program Pengembangan Karir (Career Development Program - CDP)}

Program CDP adalah bentuk peningkatan keterampilan kerja individu yang dicapai untuk mencapai karir yang diinginkan oleh karyawan dan merupakan salah satu bentuk investasi organisasi untuk karyawan (Allen et al., 2003). Program CDP dapat pula berupa transisi dari satu pekerjaan ke pekerjaan lainnya di mana ada proses pembelajaran dan pengembangan pengetahuan (Ohlott, 2004). Pemindahan karyawan ke posisi baru untuk meningkatkan pengembangan karier mereka adalah cara kunci bagi organisasi untuk berinvestasi pada karyawan. Program CDP memiliki tiga tahap, yaitu: tahap penilaian, tahap arah, dan tahap pengembangan (Gomez-meija et al., 2011). Tahap penilaian meliputi penilaian mandiri, perencanaan suksesi, dan penilaian kinerja. Tahap arahan dapat menjadi penjelasan tentang jalur karir karyawan dalam organisasi, hal ini bertujuan untuk memotivasi karyawan untuk mengembangkan karir mereka. Tahap pengembangan termasuk pendidikan formal dan pengalaman kerja (Gomez-meija et al., 2011). 
Program CDP merupakan bagian elemen terpenting dalam organisasi yang sukses yang membutuhkan peran pemimpin dalam mengoptimalkan manajemen bakat (Nair, 2013). Kepemimpinan yang efektif dapat membantu menyeimbangkan kehidupan kerja karyawan dan membantu organisasi mengidentifikasi kualitas karyawan dan retensi sebagai salah satu upaya jangka panjang untuk efisiensi organisasi (Nair, 2013). Ketika angka retensi tinggi di dalam organisasi, maka organisasi tentunya tidak perlu melakukan proses rekrutmen, yang tentunya akan menghabiskan banyak biaya, untuk menggantikan posisi kosong sebagai konsekuensi dari kehilangan karyawan. Program CDP menunjukkan pengakuan organisasi atas kontribusi karyawan dan menunjukkan bahwa organisasi mendukung karyawan untuk berkembang (Allen et al., 2003). Dengan demikian, penelitian ini ingin melihat pengaruh pelaksanaan CDP terhadap retensi karyawan Bank X.

\section{Persepsi Dukungan Organisasi (Perceived Organizational Support - POS)}

Persepsi dukungan organisasi (POS) adalah bagaimana karyawan melihat organisasi menghargai kontribusi dan kepedulian terhadap kesejahteraan karyawan dan sebaliknya untuk mencapai tujuan organisasi (Eisenberger \& Huntington, 1986; Rhoades \& Eisenberger, 2002). POS memiliki delapan indikator yang dapat digunakan untuk mengukur tingkat dukungan organisasi yaitu: organisasi menghargai kontribusi karyawan, organisasi menghargai upaya ekstra yang diberikan oleh karyawan, organisasi akan memperhatikan semua keluhan karyawan, organisasi sangat memperhatikan kesejahteraan karyawan, organisasi akan memberi tahu karyawan ketika tidak melakukan pekerjaan dengan baik, organisasi peduli tentang kepuasan umum dengan pekerjaan karyawan, organisasi menunjukkan perhatian besar bagi karyawan, organisasi merasa bangga dengan kesuksesan karyawan di tempat kerja (Rhoades \& Eisenberger, 2002). Kedelapan indikator ini akan diukur dalam bentuk aitem pada penelitian ini.

POS memiliki dampak pada beberapa keluaran perilaku karyawan dalam organisasi, di antaranya komitmen organisasi, kepuasan kerja, kinerja, tekanan, retensi karyawan, dan perilaku penarikan seperti terlambat, absen, dan turnover (Putra \& Rahyuda, 2016; Rhoades \& Eisenberger, 2002). Pada penelitian ini, POS berperan menjadi mediator dalam hubungan antara CDP dan retensi karyawan. Peneliti berasumsi bahwa persepsi dukungan dari organisasi membuat karyawan memiliki rasa memiliki, kepercayaan, dan komitmen terhadap organisasi. 
Karyawan yang merasa didukung oleh organisasi akan tinggal lebih lama karena mereka merasa memiliki kewajiban untuk tetap berada di organisasi.

\section{Hipotesis penelitian}

Berdasarkan penjelasan pada bagian pendahuluan dan telaah kajian, maka peneliti mengajukan hipotesis sebagai berikut: dukungan organisasi dapat menjadi mediator pada hubungan antara Program CDP dan retensi karyawan (Gambar 1).

Gambar 1. Model penelitian

\section{Perceived Organizational}

Support (POS)

(M)
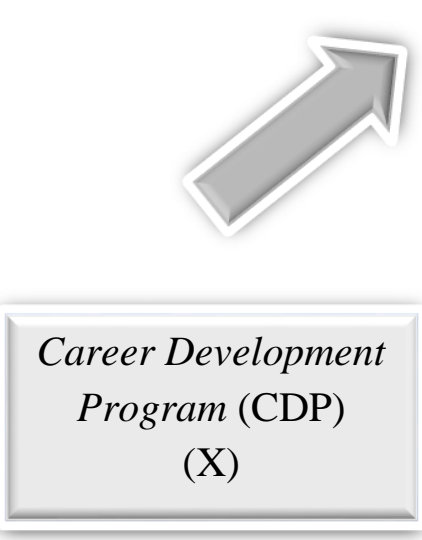
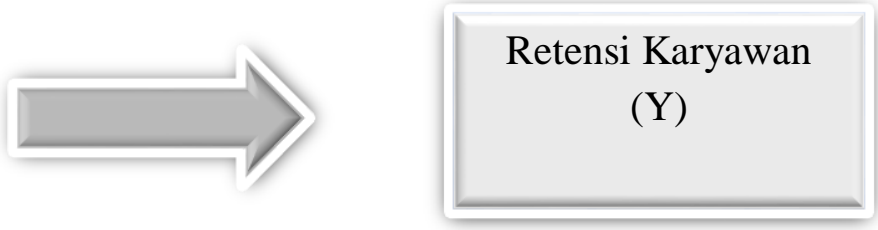

\section{METODE PENELITIAN}

\section{Pengukuran dan Prosedur}

Populasi penelitian ini terdiri dari karyawan beberapa cabang bank $\mathrm{X}$ di wilayah Jabodetabek dengan karakteristik telah menjadi karyawan tetap setingkat staff dan manajer dengan satu tahun atau lebih pengalaman kerja dalam organisasi. Kuesioner dibagikan secara daring menggunakan aplikasi google form (https://forms.gle/wGmq9jXBN7jXrjgk8). Pengumpulan data berlangsung pada 1 Maret 2020 hingga 15 Maret 2020. Kuesioner ini diisi oleh 170 peserta, dengan satu peserta bukan karyawan organisasi dan 4 orang melakukan pengisian ganda, sehingga 5 data tersebut dikeluarkan dari hasil penelitian. Responden dalam penelitian ini terdiri dari 83 responden laki-laki dan 82 responden perempuan $(\mathrm{N}=165)$, dengan 
Jurnal Riset Manajemen Sains Indonesia (JRMSI) | Vol 11, No. 2, 2020

e-ISSN: 2301-8313

http://doi.org/10.21009/JRMSI

usia rata-rata (31-40 tahun dengan persentase 52\%). Sebagian besar responden sebagai staff (73\%) (Lihat Tabel 1, 2, dan 3).

Tabel 1. Profil Responden berdasarkan Jenis Kelamin

\begin{tabular}{lcc}
\hline Jenis Kelamin & Jumlah Responden & Persentase \\
\hline Laki-laki & 83 orang & $51 \%$ \\
Perempuan & 82 orang & $49 \%$ \\
Total & 165 orang & $100 \%$
\end{tabular}

Sumber: data peneliti (2020)

Tabel 2. Profil Responden berdasarkan Usia

\begin{tabular}{lcc}
\hline Usia & Jumlah Responden & Persentase \\
\hline$<31$ tahun & 71 orang & $43 \%$ \\
$31-40$ tahun & 86 orang & $52 \%$ \\
.$>40$ tahun & 8 orang & $5 \%$ \\
Total & 165 orang & $100 \%$ \\
\hline
\end{tabular}

Sumber: data peneliti (2020)

Tabel 3. Profil Responden berdasarkan Jabatan

\begin{tabular}{lcc}
\hline Jabatan & Jumlah Responden & Persentase \\
\hline Staff & 120 orang & $73 \%$ \\
Officer & 29 orang & $17 \%$ \\
Manajer & 16 orang & $10 \%$ \\
Total & 165 orang & $100 \%$ \\
\hline
\end{tabular}

Sumber: data peneliti (2020)

Data dikumpulkan dengan menggunakan tiga kuesioner, sebagai berikut:

Retensi karyawan diukur menggunakan item yang dikembangkan Decenzo, David dan Robbins, (2002) yang kemudian di adaptasi ke dalam Bahasa Indonesia oleh Robbani (2012) (Cronbach Alpha $\boldsymbol{\alpha}=0,933$ ). Peneliti melakukan penyesuaian penggunaan kata tempat penelitian pada setiap item dengan merubahnya menjadi kata "perusahaan ini”. Masing-masing aitem dikategorisasi menggunakan skala likert 1 (Sangat tidak setuju) hingga 5 (Sangat Setuju). 
Penilaian dilakukan dengan membuat tabel distribsi frekuensi dari jawaban masing-masing aitem.

Pengukuran Career Development Program (CDP) menggunakan konsep dari Gomezmeija et al. (2011) yang telah diadaptasi ke dalam bahasa Indonesia oleh Widyatami (2016) (Cronbach Alpha $\boldsymbol{\alpha}>0,6$ untuk masing-masing dimensi). Masing-masing aitem dikategorisasi menggunakan skala likert 1 (Sangat tidak setuju) hingga 5 (Sangat Setuju). Berdasarkan penelitian yang dikembangkan oleh (Widyatami, 2016), peneliti menganalisis jawaban responden berdasarkan nilai rata-rata (mean) dengan membagi kedalam 5 kategori, yakni sangat rendah $(1-1.80)$, rendah $(1.81-2.60)$, sedang $(2.61-3.40)$, tinggi $(3.41-4.20)$ dan sangat tinggi

\section{$(4.21-5.00)$.}

Pengukuran Perceived Organizational Support (SPOS) Eisenberger menggunakan versi pendek yang terdiri dari 16 item. Alat ukur tersebut dikembangkan pertama kali oleh Eisenberger et al (1986) dengan total item sejumlah 36 item dan telah dikembangkan menjadi 16 item oleh Rhoades dan Eisenberg (2002) yang kemudian diadaptasi dan digunakan oleh Aaron (2015) ke dalam Bahasa Indonesia (Cronbach Alpha $\boldsymbol{\alpha}=0,851$ ). Masing-masing aitem dikategorisasi menggunakan skala likert 1 (Sangat tidak setuju) hingga 6 (Sangat Setuju). Berdasarkan penelitian yang dikembangkan oleh Aaron (2015), peneliti menganalisis jawaban responden berdasarkan nilai rata-rata (mean) dari POS dan membandingkan antara 2 populasi penelitian.

\section{HASIL DAN PEMBAHASAN}

\section{Uji Validitas dan Reliabilitas}

Data analisis pada penelitian ini menggunakan korelasi Pearson dan analisis regresi menggunakan program makro PROCESS (Hayes, 2018) untuk mengukur mediasi (model 4) untuk SPSS. Tabel 4 merepresentasikan pendeskripsian hasil analisa deskriptif, korelasi, dan reliabilitas antar variabel. Hasil reliabilitas Cronbach alpha dari masing-masing kuesioner menunjukkan hasil yang reliabel, di mana pengukuran Program CDP dengan menggunakan 12 aitem pertanyaan $(\alpha=0,878)$, POS dengan 16 aitem pertanyaan $(\alpha=0,770)$, dan retensi dengan 10 aitem pertanyaan $(\alpha=0,884)$ dengan taraf signifikansi $p<0,001$. Nilai Cronbach Aplha dari ketiga alat ukur lebih besar dari r-tabel $(0,1517)$. Selanjutnya, berdasarkan analisis regresi antara Program CDP dengan retensi dengan hasil Sig. $=0,980$ di mana hasil tersebut lebih besar dari 
0,05, maka dapat dikatakan terdapat hubungan linear yang signifikan antara variabel Program CDP dengan retensi. Berdasarkan hasil pengujian korelasi Pearson, didapatkan hasil korelasi antar variabel dimana hasil korelasi CDP dengan retensi di dapatkan nilai r-hitung $=0,536$, korelasi CDP dengan POS sebesar r-hitung $=0,530$, dan korelasi POS dengan Retensi sebesar rhitung $=0,546$. Jika dibandingkan dengan r-tabel $(0,1519)$, maka hasil r-hitung dari ketiga variabel > r-tabel dengan nilai Sig. $p>0,01$, maka dapat disimpulkan bahwa terdapat korelasi yang signifikan diantara ketiga variabel yang diteliti.

Tabel 4. Nilai rerata, deviasi standar, korelasi, dan reliabilitas alat ukur.

\begin{tabular}{lcccccc}
\hline Variabel & Cronbach Alpha & Mean & SD & CDP & POS & Retensi \\
\hline CDP & 0,878 & 53,43 & 6,4 & - & \\
POS & 0,770 & 56,71 & 10,66 & $0,530^{* *}$ & - & \\
Retensi & 0,884 & 33,52 & 4,7 & $0,536^{* *}$ & $0,546^{* *}$ & - \\
\hline
\end{tabular}

**. Correlation is significant at 0,01 level (2-tailed)

\section{Pengujian Hipotesis}

Tabel 5. menampilkan hasil analisa data menggunakan program makro PROCESS. Hasil menunjukkan bahwa Program CDP dapat memprediksi Retensi secara signifikan $(\beta=0,252$, $S E=0,054, p<0,001)$. Selain itu, hasil analisa menunjukkan bahwa Program CDP dapat memprediksi POS secara signifikan $(\beta=0,883, S E=0,111, p<0,001)$. Hasil juga menunjukkan POS dapat memprediksi retensi secara signifikan $(\beta=0,160, S E=0,032, p<0,001)$. Hasil mediasi menunjukkan bahwa hubungan antara Program CDP dan retensi dimediasi oleh POS secara signifikan $\mathrm{F}(2,163)=50,132, p<0,001, \mathrm{R} 2=0,382, \mathrm{LLCI}=0,073$ dan ULCI = 0,219). Dengan demikian dapat disimpulkan bahwa terdapat hubungan tidak langsung antara Program CDP terhadap retensi melalui mediator POS, sehingga hipotesis dapat diterima. 
Tabel 5 Hasil analisa mediasi.

\begin{tabular}{|c|c|c|c|c|c|c|c|c|}
\hline & & \multicolumn{7}{|c|}{ Consequent } \\
\hline & & \multicolumn{4}{|c|}{ M (POS) } & \multicolumn{3}{|c|}{ Y (Retensi) } \\
\hline Antecedent & & Coeff. & $\mathrm{SE}$ & $p$ & & Coeff. & $\mathrm{SE}$ & $p$ \\
\hline$X(C D P)$ & $\mathrm{a}$ & 0,883 & 0,111 & $<0,001$ & $c^{\prime}$ & 0,252 & 0,054 & $<0,001$ \\
\hline$M(P O S)$ & & - & - & - & $\mathrm{b}$ & 0,160 & 0,032 & $<0,001$ \\
\hline \multirow[t]{3}{*}{ Constant } & $\mathrm{i}_{1}$ & 9,538 & 5,952 & 0,111 & $\mathrm{i}_{2}$ & 10,948 & 2,460 & $<0,001$ \\
\hline & & \multicolumn{4}{|c|}{$\mathrm{R} 2=0,281$} & \multicolumn{3}{|c|}{$\mathrm{R} 2=0,382$} \\
\hline & & \multicolumn{4}{|c|}{$F(1,164)=63,694, p<0,001$} & \multicolumn{3}{|c|}{$\mathrm{F}(2,163)=50,132, p<0,001$} \\
\hline
\end{tabular}

Sumber: Data peneliti (2020)

\section{DISKUSI}

Penelitian ini bertujuan untuk menguji peran dukungan organisasi (POS) pada hubungan antara program CDP dan retensi karyawan. Dari hasil pengujian hipotesis mengunakan analisa mediasi didapatkan bahwa POS dapat memediasi hubungan antara Program CDP dan retensi karyawan. Hasil ini sejalan dengan penelitian sebelumnya bahwa bila organisasi memperhatikan dan memberikan dukungan pada karyawan berupa manajemen karir, maka karyawan akan cenderung untuk tetap bekerja di organisasi (Allen et al., 2003; Perrine, 2005). Dapat dikatakan bahwa karyawan Bank X setuju bahwa Program CDP mempengaruhi retensi, dan dukungan yang diberikan organisasi semakin memperkuat retensi mereka. Dengan adanya dukungan organisasi pada perencanaan karir karyawan akan membuat karyawan mempertimbangan untuk tetap tinggal di organisasi. Kejelasan program pengembangan karir di dalam organisasi dapat membuat karyawan memahami jenjang karir dan tingkatan pengetahuan yang harus mereka miliki guna mendukung efektifitas pekerjaan mereka.

Karyawan suatu organisasi merupakan salah satu sumber daya yang tidak terlihat dalam organisasi yang harus diperhatikan dan harus dikembangkan sering dengan berjalannya perkembangan organisasi (Kaplan \& Norton, 2004). Hasil analisa penelitian ini mengemukakan bahwa terdapat hubungan antara Program CDP dengan POS. Pemberian pelatihan dan tambahan pengetahuan kepada karyawan merupakan bentuk investasi organisasi terhadap karyawan. Dengan pemberian kesempatan bagi karyawan untuk mengembangkan pengetahuannya akan membuat karyawan turut serta menyumbangkan pemikirannya guna menunjang perkembangan organisasi. Program CDP tidak selalu berbentuk promosi, tetapi juga dapat berupa 
pengembangan karir melalui pengalaman kerja (Gomez-meija et al., 2011). Ohlott (2004) mengatakan bahwa selain pengalaman di tempat kerja, pengembangan karir juga dapat menjadi transisi dari satu pekerjaan ke pekerjaan lainnya di mana ada proses pembelajaran dan pengembangan pengetahuan. Memindahkan karyawan ke posisi baru yang meningkatkan pengembangan karier mereka adalah cara kunci bagi organisasi untuk berinvestasi pada karyawan.

Sebagai upaya pengembangan pengetahuan dengan menggunakan metode pembelajaran, sejumlah pelatihan kerap dilakukan dalam organisasi. Tidak jarang dilakukan pembaharuan pengetahuan untuk mengingatkan kembali dan memperdalam pengetahuan karyawan dan menyesuaikan pengetahuan tersebut dengan fakta dilapangan. Strategi pemindahan karyawan dari satu bagian ke bagian lainnya pun turut dilakukan di Bank X. Selain itu kerap dilakukan sharing moment, dimana karyawan secara bergantian menjelaskan mengenai Standar Operasional Prosedur (SOP) di bagiannya kepada karyawan lain. Hal ini merupakan salah satu upaya untuk menyalurkan pengetahuan organisasi kepada seluruh karyawan dengan tujuan agar karyawan mendapatkan pengetahuan mengenai seluruh aspek bisnis perbankan yang ada. Hal ini sesuai dengan apa yang Wayne et al. (1997) ungkapkan bahwa pengembangan pengetahuan karyawan dapat dilakukan dengan cara pemberian training baik formal maupun informal kepada karyawan. Tujuan pemberian fasilitas pengembangan karyawan merupakan salah satu bentuk pertukaran yang dilakukan organisasi kepada karyawan. Mengutip apa yang disampaikan Eisenberger \& Huntington (1986), proses pengoperasian organisasi merupakan bentuk pertukaran antara karyawan dengan organisasi, karyawan memberikan kinerja yang baik guna mencapai tujuan organisasi, dan organisasi memberikan kompensasi kepada karyawan, baik berupa penghargaan (seperti gaji dan promosi) maupun dalam bentuk pengembangan karyawan.

Perencanaan jenjang karir hendaknya dikomunikasikan secara terbuka dengan karyawan. Dengan mengetahui jenjang karir diharapkan karyawan memiliki motoivasi dan rancangan masa depan di dalam organisasi. Pengenalan segala bidang di dalam organisasi kerap dilakukan di Bank X, dimana manajemen berharap agar karyawan memiliki wawasan yang luas dan menyeluruh terhadap segala aspek di dalam organisasi. Sejalan dengan strategi Bank X yang lebih mengutamakan pengembangan kompetensi melalui peningkatan keterampilan teknis dan pengembangan bakat dalam rangka menciptakan talent pool sebagai regenerasi pemimpin di dalam organisasi merupakan bentuk dukungan organisasi dalam pengembangan karir karyawan. 
Strategi ini cukup tepat, karena pengembangan karyawan tidak selalu hanya terpaku pada promosi karyawan, pengalaman kerja melalui rotasi, mutasi dan promosi di bagian lain juga merupakan bentuk pengembangan karyawan (Gomez-meija et al., 2011; McCall et al., 1988; Noe et al., 1997). Pemberlakuan rotasi dan mutasi karyawan bertujuan agar karyawan tidak hanya menjadi suatu spesialis dalam satu bidang pekerjaan, namun lebih kepada generalis dimana hal tersebut dibutuhkan dalam pelaksanaan bisnis perbankan Bank X.

Rotasi dan mutasi dapat disesuaikan dengan resiko pekerjaan yang ada di dalam organisasi. Untuk itu diperlukan analisa jabatan dengan menyeluruh di masing-masing bagian. Dengan berpindah dari satu bagian ke bagian lainnya, karyawan merasa dipercaya oleh organisasi untuk bekerja dengan level pekerjaan yang lebih menantang. Kepercayaan yang diberikan organisasi kepada karyawan merupakan salah satu dukungan organisasi dalam bentuk penghargaan terhadap karyawan. Dukungan dari organisasi membuat karyawan memiliki rasa memiliki, kepercayaan, dan komitmen terhadap organisasi. Karyawan yang merasa didukung oleh organisasi akan tinggal lebih lama karena mereka merasa memiliki kewajiban untuk tetap berada d iorganisasi (Wayne et al., 1997).

\section{KESIMPULAN DAN SARAN}

\section{Kesimpulan}

Melalui penelitian ini di dapatkan hasil bahwa POS dapat memediasi hubungan antara Program CDP dan retensi karyawan. Di mana dengan adanya dukungan organisasi dalam pengembangan karir karyawan, organisasi dapat dinilai peduli dengan kesejahteraan karyawan. Pengembangan karir tidak hanya berupa promosi tetapi juga berupa pengembangan pengetahuan karyawan, baik melalui pemberian training maupun pengalaman kerja melalui rotasi dan mutasi kerja. Dengan pemberian kesempatan kepada karyawan untuk menempati posisi lain di dalam organisasi diharapkan akan menimbulkan rasa bahwa organisasi memberikan kepercayaan kepada karyawan untuk terus berkembang. Selain itu, pengembangan pengetahuan karyawan, baik melalui training maupun perputaran jabatan, merupakan bentuk investasi organisasi terhadap karyawan. Dengan kejelasan alur pengembangan karir dan adanya kesempatan bagi karyawan untuk mengembangan pengetahuannya diharapkan karyawan akan tetap tinggal di organisasi dan turut serta menyumbangkan ide-ide serta pengetahuannya untuk pengembangan organisasi. 


\section{Saran}

\section{Bagi Perusahaan}

Hasil penelitian ini mengungkapkan bahwa Program CDP penting bagi peningkatan angka retensi karyawan. Kejelasan karir hendaknya dapat lebih diatur dengan melakukan analisis jabatan dengan peningkatan sejumlah resiko dalam pekerjaan sebagai salah satu pertimbangan sebelum dilakukannya rotasi dan mutasi. Dengan demikian, akan didapatkan alur jenjang karir yang menjanjikan bagi karyawan. Selain itu, jenjang karir hendaknya di bicarakan secara terbuka antara Menejemen dengan karyawan, sehingga karyawan dapat merencakan karir dan pengetahuan yang harus mereka miliki jika ingin beralih kesuatu posisi baru.

\section{Penelitian Selanjutnya}

Dikarenakan keterbatasan peneliti dalam mengambil jumlah responden, maka akan lebih baik dalam penelitian selanjutnya dapat menggunakan jumlah responden yang lebih besar sehingga hasil yang diperoleh lebih bermakna. Penelitian juga dapat dilakukan pada bank swasta lain di Indonesia yang memiliki kebijakan berbeda dari Bank $\mathrm{X}$ sehingga mereka bisa mendapatkan gambaran tentang retensi di industri perbankan secara umum. Peneliti harus lebih bisa memantau ketika responden mengisi kuesioner sehingga hasil yang diperoleh tidak bias dan bukan penilaian yang idealnya ada di organisasi. Pemantauan akan menghindari kesalahan atau data manipulatif dari responden. Selain itu, variabel lain yang dapat mempengaruhi retensi karyawan dapat dipertimbangkan, seperti gaji dan tunjangan maupun gaya kepemimpinan, dan juga variabel lain yang dapat memediasi hubungan antara program pengembangan karir dan retensi. Dapat pula mempertimbangkan metode analisis moderator dalam analisis statistik jika diperlukan. 
Jurnal Riset Manajemen Sains Indonesia (JRMSI) | Vol 11, No. 2, 2020 http://doi.org/10.21009/JRMSI

e-ISSN: 2301-8313

\section{DAFTAR PUSTAKA}

Aaron, D. (2015). Perbedaan Perceived Organizational Support antara Karyawan Generasi X dan Karyawan Generasi Y pada PT. Z.

Allen, D. G., Shore, L. M., \& Griffeth, R. W. (2003). The Role of Perceived Organizational Support and Supportive Human Resource Practices in the Turnover Process. Journal of Management, 29(1), 99-118. https://doi.org/10.1177/014920630302900107

Eisenberger, R., \& Huntington, R. (1986). Perceived Organizational Support.

Fukofuka, S. (2014). Factors That Predict Employee Retention in Profit and Not-for-Profit Organization. Factors That Predict Employee Retention in Profit and Not for -Profit Organization, 2(4), 1-8. www.eajournals.org

Gomez-meija, L. R., Balkin, D. B., \& Cardy, R. L. (2011). Managing Human Resources (7 th editi). Prentice Hall.

Hayes, A. F. (2018). Introduction to Mediatioan, Moderation, and Conditional Process Analysis : a Regression-based Approach (T. D. Little (ed.)). The Guilford Press.

Jennifer, C. A. (2005). HR How To Employee Retention. J.D. CCH Incorporated.

Kaplan, R. S., \& Norton, D. P. (2004). Strategy Maps : Converting Intangible Assets into Tangile Outcomes. Harvard School Publishing Corporation.

Kassa, T. (2015). Employee Motivation and its Effect on Employee Retention in Ambo Mineral Water Factory. International Journal of Advance Research In, 3(3), 2321-2782. www.ijarcsms.com

Khan, R. A. (2014). The Impact of Career Planing and Development On Job Satisfaction and Retention in Pakistan Banking Sector. Global Management Journal of Academic and Corporate Studies, 4(2), pp: 109116.

Kossivi, B., Xu, M., \& Kalgora, B. (2016). Study on Determining Factors of Employee Retention. Open Journal of Social Sciences, 04(05), 261-268. https://doi.org/10.4236/jss.2016.45029

McCall, M. W., Lombardo, M. M., \& Morrison, A. M. (1988). The Lessons of Experience: How Successful Executives Develop on the Job. New Lexington Press.

Mohamad, K. (2019). Gelombang PHK 40.000 Pegawai Bank. Infobank: Analisis Stategi Perbankan Dan Keuangan, 20-25. 
Mohapatra, S., Agraw, A., \& Satpathy, A. (2016). Designing Knowledge Management- Enabled Business Strategies. Springer.

Nair, P. (2013). Effective Leadership-Employee Retention-Work Life Balance: A Cyclical Continuum. IOSR Journal of Business and Management, 10(3), 80-86. https://doi.org/10.9790/487x-1038086

Ohlott, P.J. (2004), “Job assignments”, in McCauley, C.D. and Van Velsor, E. (Eds), The Center for Creative Leadership: Handbook of Leadership Development, 2nd ed., Wiley, New York, NY

Oladapo, V. (2014). The impact of talent management on retention. Journal of Business Studies Quarterly, 5(3), 19.

Perrine, P. (2005). Integrating talent management. Human Resources Management.

Prince, J. B. (2005). Career-focused employee transfer processes. Career Development International, 10(4), 293-309. https://doi.org/10.1108/13620430510609136

Ragupathi, D. (2013). The Employee Retention Practices of MNC`S in Hyderabad. Research Journal of Management Sciences, 2(4), 21-24.

Rhacyella Rattu, B. R., \& J Tielung, M. V. (2018). Influence of Work Environment and Employee Motivation on Employee Retention At Siloam Hospital Manado Pengaruh Lingkungan Kerja Dan Motivasi Karyawan Terhadap Retensi Karyawan Di Rumah Sakit Siloam Manado. Jurnal EMBA, 6(3), 1568-1577.

Rhoades, L., \& Eisenberger, R. (2002). Perceived organizational support: A review of the literature. Journal of Applied Psychology, 87(4), 698-714. https://doi.org/10.1037/00219010.87.4.698

Robbani, J. (2012). Hubungan Reward dengan Retensi Karyawan pada Divisi Multimedia PT Telekomunikasi Indonesia,Tbk.

Singh, N., \& Sharma, L. . (2018). Antecedents to Employee Retention in Banking Industry : An Empirical Enquiry of Individual Related Variables. January 2017.

Umam, K. (2010). Perilaku Organisasi. CV Pustaka Setia.

Wayne, S. J., Shore, L. M., \& Liden, R. C. (1997). Perceived organizational support and leadermember exchange: A social exchange perspective. Academy of Management Journal, 40(1), 82-111. https://doi.org/10.2307/257021

Widyatami, K. A. (2016). Pengaruh Career Development terhadap Employee Retention dengan 
Jurnal Riset Manajemen Sains Indonesia (JRMSI) | Vol 11, No. 2, 2020 e-ISSN: 2301-8313 http://doi.org/10.21009/JRMSI

\section{Employee Engagement sebagai Variable Mediasi.}

Wijayanti, C., \& Nurtjahjanti, H. (2015). Perceived Organizational Support Dan Retensi Pada Karyawan Pkwt Proyek Dermaga Petikemas Pt. Pp (Persero) Jakarta. Empati, 4(1), 49-54. 